\title{
THE MACROPLAN FOR GERIATRIC CARE
}

\author{
P. DE V. MEIRING, M.B., B.Ch., F.R.C.P. (Edin), M.R.C.P. (Lond)*
}

\begin{abstract}
SUMMARY
A macroplan and a microplan for geriatric care are oullined. The ternus geriarric medicine and the geriatric palient are defined. A trpical extended community geriatric ream is illustrated by means of a table, as well as an overall plan for coordinating these services. The expectations of the geriatrician in respect of the contributions to be made by the physiotherapist are discussed inder five headings.
\end{abstract}

King and Martidipoero (1978) define a microplan as an attempt to identfy a subsystem with a total health care system and to build the fragments of this system into an entity, the microplan, which must fit into the total system and improve its functioning.

These authors use the term macroplan to describe national health plans of the traditional kind; these, when applied to geriatrics, will include consideration of social and demographic factors and the total planning for care of geriatric patients in hospitals and the community by all agencies and disciplines that must be involved in delivering such care. There will therefore be a strong element of statutory control and coordination if the macroplan is to be an efficient medium for care of the frail and sick elderly.

As by no means all elderly persons can be classified as geriatric, it is necessary to define the term as that branch of general medicine concerned with the clinical, preventive. remedial and social aspects of illness in the elderly.

The geriatric patient can be defined (Shapiro. 1979) as an elderly person who is not able or likely to be able to mainrain independence in the community withoul help in some of the supportive, basic or remedial needs.

It must by now be apparent that geriatric care cannot be the exclusive monopoly of the doctor since a number of disciplines and techniques, as well as voluntary and statutory agencies, must be employed to deliver care on a broad front in hospitals, nursing homes, old age homes, "sheltered housing and the community. A macroplan will be made up of a number of microplans. In enunciating the principles of

* William Slater Professor and Head of Geriatric Unit, University of Cape Town.

Received 13 October 1982.

\section{OPSOMMING}

'n Makroplan on 'n mikroplan vir geriarriese sorg word geskets. Die terme geriatricse geneeskinde en die geriantess' pasient word gedefiniecr. '" Tipiese uitgebreide gemeenskaps geriarriese span. asook 'n oorkoepelende plan om hierdie chenste te koördineer, word deur middel van rabelle geillustreer. Die verwagfingevan die geriatriese geneesheer ten opsigte van die bydraes wat deur die fisioterapeut gemaak kan word, word onder vuf hoofde bespreck.

macroplanning in this context, it is necessary to lay down a number of microplans and then to indicate how best these can be coordinated and applied in the most cost effective way. In day to day health care of aged persons, the geriatrician may be looked upon as the conductor of the orchestra, who, while having a vital coordinating role, eannot produce good music unless all the individual players are competent, disciplined and cooperative. Likewise, no matter how good the individual players may be, a cacophony will result from their totally uncoordinated efforts in attempting to render a difficult performance without a conductor. The various disciplines, skills and agencies whose microplans for geriatric practice must contribute to thef overall macroplan, are briefly indicated so that the various workers in the field can have some idea where their individual contributions will fit into the general scheme of things.

TABLE I shows the composition of a typical extended community geriatric team. Rather than a geographically located entity, this team will (particularly in an environment where geriatric medicine is not yet well developed) tend to be constituted by a list of persons or agencies, available when required. However, in a well-run Geriatrie Unit there will be regular multidisciplinary case discussions as part of the practical work of the Unit and it is when this is wcll developed and pertinent to the work load that a Geriatric Unit is at its best. It is, however, only those most closely concerned with direct day to day care that will meet in the wards or outpatient clinics in hospitals, clinics and day hospitals.

An overall plan for coordinating these many services has been presented (Meiring, 1982a) as indicated in TABLE 2, whilst the place of hospital-based services is illustrated in fig. 1 . 


\section{TABLE 1}

THE DISCIPLINES AND AGENCIES INCLUDED IN THE TYPICAL GERIATRIC SERVICE *

1. Geriatrician or doctor with interest in care of the aged.

2. Other medical, surgical and dental specialists and practitioners as required.

3. Hospital, community liaison and community nursing services.

4. Physiotherapist.

5. Occupational therapist.

6. Social worker.

7. Dietician.

8. Speech therapist.

9. Optometrist.

10. Hospital laboratory and radiological staff and other technicians (orthopaedic workshops, etc.).

11. Hospital administrators and planners and legislators.

12. Hospital domestic staff and drivers.

13. Chiropodists.

14. Voluntary workers, home helps, visitors.

15. Community agencies for care of the aged.

16. 'The informal sector' eg. school children, church members, the granny next door, etc., etc.

* As all elements have a role without which the team cannot function optimally the order in which they are arranged does not imply any precedence.

\section{TABLE 2}

The scheme for overall planning for care of the elderly:

A. DEFINITION OF GERIATRICS AND THE GERIATRIC PATIENT.

B. CARE OF THE ELDERLY IN THE COMMUNITY AND HOSPITAL.

1. The doctor and allied health care workers

2. The overall plan for care of the aged

2.1 The clinical and preventive role of the doctor

2.2 Learning and teaching roles of the doctor

2.3 The team approach to hospital, community and social factors in geriatric care

2.4 The place of hospital based services

2.5 Care of the terminally ill.

3. Statutory and coordinated eare for the elderly on a nation-wide basis

3.1 Health Act of 1977 and other legislation

3.2 Health Matters Advisory Committee and its Subcommittee for Health Services for the Aged

3.3 National Network of regional coordinating committees in major centres

3.3.1 Coordinating work of:

3.3.1.1 State Health: Mental health, District surgeons, District nursing services

3.3.1.2 Provincial health authorities

3.3.1.3 Medical association

3.3.1.4 Local authorities

3.3.1.5 Voluntary bodies and agencies.

\section{TABLE 3}

Percentage population 65 and over, 1970 and projected in year 2000 .

\begin{tabular}{ccc|cc|cc|cc}
\multicolumn{4}{c}{ Black } & \multicolumn{2}{c}{ White } & \multicolumn{2}{c}{ Coloured } & \multicolumn{2}{c}{ Asian } \\
1970 & 3.22 & 4.01 & 5.45 & 7.59 & 2.7 & 3.3 & 1.8 & 1.6 \\
2000 & 2.97 & 4.17 & 7.7 & 9.9 & 3.0 & 3.62 & 2.7 & 3.9 \\
\hline
\end{tabular}

A microplan for ge riatric practice by doctors caring for the aged has been described (Meiring, 1982b), making specific mention of the members of the team that are called upon, including the physiotherapist, and emphasizing the paramount importance of interdisciplinary coordination. Population projections (TABLE 3) show that care of the aged can be expected to absorb an ever-inceasing slice of the available health care resources.

Isaacs (1969) described the geriatric patient as an elderly person, often of advanced age, often living alone or having lost contact with family or friends, who may be a spinster. widower or bachelor and who suffers from two or more disabling disorders which included strokes, gait loss, falls. mental impairment and incontinence. Based upon the first hundred referrals to the Geriatric Unit of Groote Schuur Hospital and the University of Cape Town, the following 
Fisioterapie, Desember 1982, Deel 38, Nr. 4

tentative definition may be offered: The gerialric patient is an elderly person whose independence is impaired or lost because of the simullaneous presence of tw'o or nore problems of a clinical and social nature. Such a patient is likely to be of a relatively advanced age, to be socially and cconomically disadvantaged and to have a combination of disabling disorders or symploms that commonly include strokes. incontinence, crippling cardio-pulmonary disorders, loss of mobility. falls and psuchiatric abnormalitics.

From these definitions, the expectations of the geriatrician in respect of the contributions to be made by the physiotherapist begin to form a clearer image. With this as a basis for further discussion and cooperation between these two disciplines, it could lead to the formulation of a microplan for physiotherapy for the aged. These expectations can be examined as follows:

\section{THE CLINICAL AND PREVENTIVE RULES OF THE PHYSIOTHERAPIST.}

The physiotherapist has to study the disease spectrum in the aged and the peculiarities and disabilities of these diseases in their total perspective to formulate the training and work content required to meet these challenges. Particular attention should be paid to educating doctors and preventive health authorities to refer cases with early or mild disabilities such as minimal osteoarthritis, minimal strokes and muscle weakness of the very aged. Research could be directed towards finding the optimal solutions to these problems and the best modalitics of treatment. Cooperation in the total effort of rehabilitation will thus be very important.

\section{THE LEARNING AND TEACHING ROLES OF THE PHYSIOTHERAPIST.}

These are intimately bound up with the clinical and preventive roles suggested above, the three pillars of any academic discipline being research, service and teaching.

\section{THE TEAM APPROACH}

A productive, multidisciplinary team effort has been started in the Geriatric Unit at Conradie Hospital and it is worthy of note that the Regional Director of State Health has recently appointed a District Physiotherapist.

The report on home care teams in Canada has already been mentioned briefly (Shapiro, 1979) in referring to the attributes of the geriatric patient. In this report Shapiro describes in detail the concept of home care teams as developed in Canada, and Hunt and Crichton (1977) have described how the development of the hospital-like home care in Saskatoon resulted in a marked cost reduction as compared to institutional care. As physiotherapists play a vital role in these community services, and we have hardly scratched the surface of this potential development in South Africa, a vast field of study and development is open and offers a very exciting challenge to the physiotherapy profession in the years ahead, provided it is matched by sufficient funding to make it possible. The potential for cost saving has, however, been pointed out so that this will be money well spent.

\section{THE PLACE OF THE PHYSIOTHERAPIST IN HOSPITAL-BASED PROGRAMMES.}

As in the clinical role described above, study of the special problems of the elderly and a willingness to work in an extended team have potential for great development in producing the hospital-based teams that form such an essential and successful part of the function of British Geriatric Units.

\section{CARE OF THE PATIENT IN LONG STAY INSTITUTIONS FOR CARE OF THE AGED.}

Here maintaining mobility for as long as possible is essential and in the presence of staff shortages this implies group activity, exercises and games. Music is an ideal medium for this and there have been requests to establish a post-graduate course in remedial music. The potential for close cooperation between team members is enormous and offers great scope for improvement of the often dreary quality of life for the inhabitants of long stay facilities.

\section{CONCLUSION}

The synthesis of microplans for geriatric care by various disciplines concerned with this service with suitable coordination and statutory controls, can be expected to result in a total preventive and curative service for the elderly. In Great Britain total care for the aged is well developed, but this itself has resulted in a number of problems as pointed out by Picton Williams (1981) and it would be a pity in a country like South Africa, where geriatrics is just emerging as a multidisciplinary specialty in its own right, to dissipate our energies and scarce resources by having to correct costly mistakes. It is for this reason that it has been thought necessary to commence an examination of the roles of the individual disciplines and to call for definitions of their functions in a series of microplans. These in turn will finally add up to a holistic concept of care for the aged, the so-called macroplan for geriatric care, and the purpose of this paper is to introduce the general concept to open further discussion towards this ideal.

\section{References}

Hunt, T. E. \& Crichton, R. D. (1977). One third of a million days to care at home 1959 to 1975. Canad. Med. Ass. J. 116, 1351-1355.

Isaacs, B. (1969). Some characteristics of geriatric patients. Scolt Med J, 14, 243-251.

King, M. H. \& Martodipoero, S. (1978). Health microplanning in developing countries. Int. J. Health Serv. 4 , 653-664.

Meiring, P. de V. (1982a). Planning for care of the aged. The aged in a modern society, a selection of lectures at the 1982 Summer School. Department of Extra-Mural Studies, University of Cape Town.

Meiring, P. de V. (I982b). Who cares? A microplan for geriatric practice. $S$ Afr Med J 62, 391-393.

Picton Williams, T. C. (1981). The future of geriatric medicine. I $R$ Coll Physicians London 1, 45-47.

Shapiro, E. (1979). Home care: a comprehensive overview. Policy Planning and Information Branch. Department of National Health and Welfare. Ottawa. 